\title{
On the position of subjects in Spanish: Evidence from code-switching
}

Bradley Hoot

DePaul University

bhoot@depaul.edu
Shane Ebert

University of Illinois, Chicago

sebert2@uic.edu

\section{Supplementary File 1}

Appendix: Mean ratings and response distribution for code-switching stimuli

Table A.1: Mean ratings by condition.

\begin{tabular}{|l|l|l|l|l|l|}
\hline Condition & C & T & $\begin{array}{l}\text { Subject } \\
\text { Position }\end{array}$ & Example & $\begin{array}{l}\text { Mean } \\
\text { rating }\end{array}$ \\
\hline Th-En-Pre & That & Eng & Pre & $\begin{array}{l}\text { Qué piensa tu padre that your brothers have } \\
\text { bought at the store? }\end{array}$ & 5.13 \\
\hline Th-En-Pos & That & Eng & Post & $\begin{array}{l}\text { Qué piensa tu padre that have bought your } \\
\text { brothers at the store? }\end{array}$ & 2.97 \\
\hline Th-Sp-Pre & That & Span & Pre & $\begin{array}{l}\text { What does your dad think that tus hermanos } \\
\text { han comprado en la tienda? }\end{array}$ & 5.13 \\
\hline Th-Sp-Pos & That & Span & Post & $\begin{array}{l}\text { What does your dad think that han comprado } \\
\text { tus hermanos en la tienda? }\end{array}$ & 3.51 \\
\hline Qu-En-Pre & Que & Eng & Pre & $\begin{array}{l}\text { Qué piensa tu padre que your brothers have } \\
\text { bought at the store? }\end{array}$ & 4.37 \\
\hline Qu-En-Pos & Que & Eng & Post & $\begin{array}{l}\text { Qué piensa tu padre que have bought your } \\
\text { brothers at the store? }\end{array}$ & 2.34 \\
\hline Qu-Sp-Pre & Que & Span & Pre & $\begin{array}{l}\text { What does your dad think que tus hermanos } \\
\text { han comprado en la tienda? }\end{array}$ & 5.55 \\
\hline Qu-Sp-Pos & Que & Span & Post & $\begin{array}{l}\text { What does your dad think que han comprado } \\
\text { tus hermanos en la tienda? }\end{array}$ & 4.98 \\
\hline
\end{tabular}




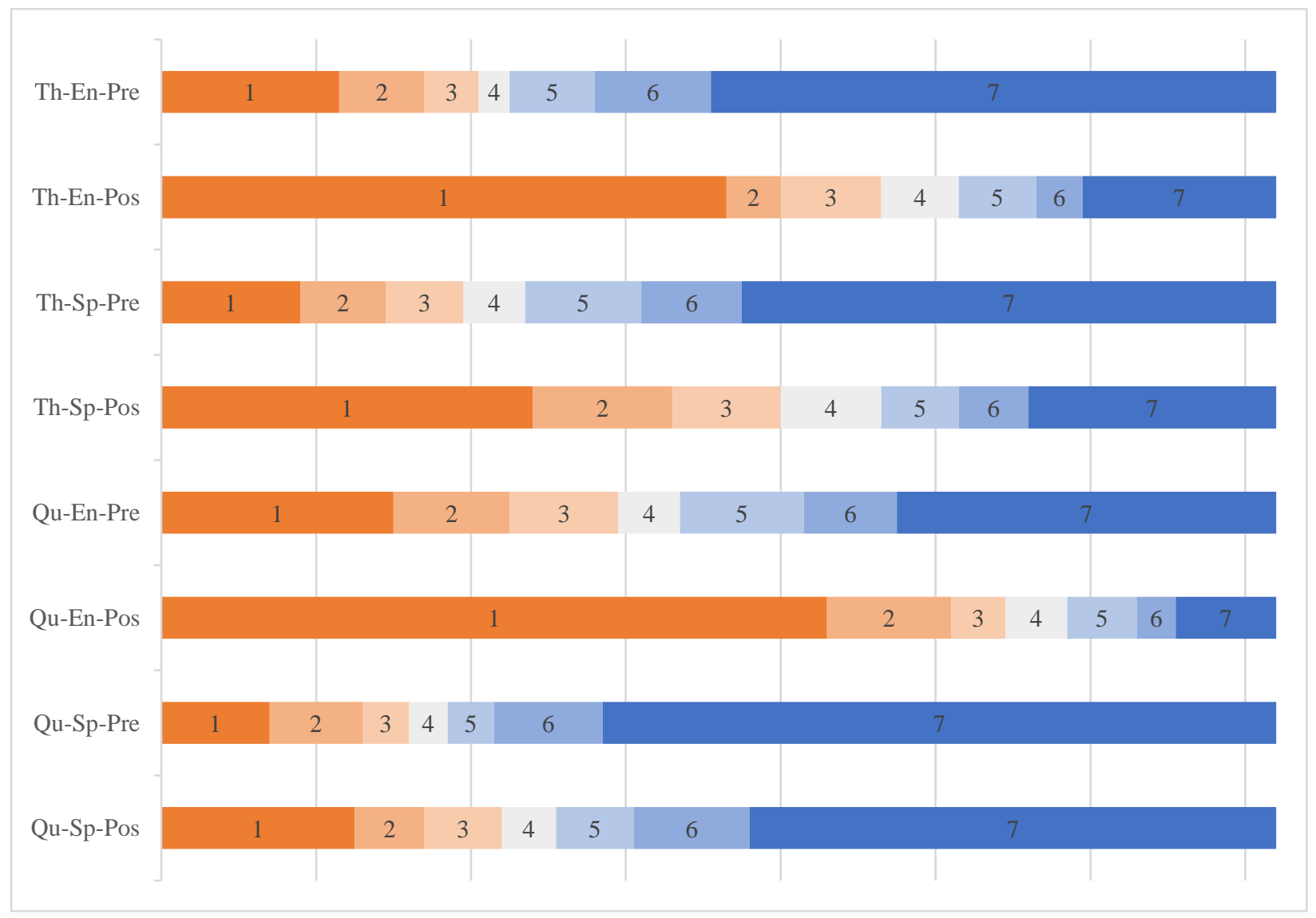

Figure A.1: Distribution of ratings by condition. 